\title{
Analytical techniques for the estimation of sulphite binding components in ciders and wines
}

\author{
Andrew G. H. Lea,* Graeme D. Ford \& Susan Fowler \\ Reading Scientific Services Ltd, The University, Whiteknights, Reading RG6 6LA, UK
}

(Received 11 August 1999; Accepted in revised form 27 October 1999)

\begin{abstract}
Summary A rapid high performance liquid chromatography (HPLC) method based on the formation of dinitrophenylhydrazine (DNPH) derivatives was developed for the analysis of the major sulphite binding carbonyls in fermented ciders (acetaldehyde, pyruvate, $\alpha$-ketoglutarate, galacturonic acid and L-xylosone). The synthesis of the DNPH derivative of L-xylosone, for use as an analytical standard, is also described. These data were used to calculate the predicted sulphite binding power of fermented ciders at various levels of free sulphur dioxide. Analysis of free and bound sulphur dioxide in the ciders, after equilibration with known amounts of added sulphite, was used to calculate the experimental sulphite binding power. These techniques were applied to a major study of sulphite binding in ciders which is reported in an accompanying paper.
\end{abstract}

Keywords Cider, HPLC, L-xylosone, sulphite binding, sulphur dioxide, wine.

\section{Introduction}

The sulphite binding power of ciders and wines is of considerable interest when sulphur dioxide is used as an anti-microbial and anti-oxidant agent in these products. Since the limits of its usage are set by legislation in most countries, it is important that it is not wasted by ineffective binding to other carbonyl containing constituents of the beverages.

The classical technique for identifying and estimating sulphite binders in ciders was developed by Burroughs \& Sparks (1964), who demonstrated that the major sulphite binders are the three metabolic carbonyls resulting from yeast action (acetaldehyde, pyruvate and $\alpha$-ketoglutarate). Glucose and galacturonic acid (resulting from pectin breakdown) also contribute. A specific binder associated with ciders is L-xylosone, which results from the breakdown of ascorbic acid in the presence of sulphite (Whiting \& Coggins, 1960). Other carbonyls with high binding power are those such as 5-keto fructose and 2,5

\footnotetext{
* Correspondent: Fax: +44 118986 8932;

andrew.gh.lea@rssl.co.uk
}

diketo gluconate which result from the microbial activity associated with rotten fruit (Burroughs \& Sparks, 1973a, b, c)

As part of a major project to understand these factors in fermented apple ciders (Jarvis \& Lea, 2000), this paper describes:

1 the development of an high performance liquid chromatography (HPLC) methodology for analysis of carbonyl sulphite-binders;

2 the determination of experimental sulphite binding power by the measurement of free and total $\mathrm{SO}_{2}$ after the addition of standard amounts of sulphite;

3 the use of the HPLC data for the calculation of predicted sulphite binding power;

4 the synthesis of the DNPH derivative of Lxylosone, which was required for this work but is unavailable commercially.

\section{Chromatographic requirements and development}

The analytical technique developed by Burroughs \& Sparks (1964) involved the separation of the hydroxysulphonates of the binding carbonyls on a column 
of anion exchange resin eluted with an increasing concentration of metabisulphite solution. Individual fractions were collected, desulphited and then titrated with iodine to provide peaks for quantification. Each peak was then identified by a combination of chromatographic and derivatization techniques. This method is conceptually elegant since it makes use of the property under investigation (sulphite binding itself) to generate the data. However, it is slow and tedious by modern standards and is unsuited for conversion to routine HPLC use.

Methods for the determination of the three metabolic carbonyls (acetaldehyde, pyruvate and $\alpha$ ketoglutarate) by enzymic redox reactions utilizing the spectrophotometric change in the co-factors NAD/NADH have been widely described and appropriate enzymes are commercially available. However, such methods by definition only determine one target compound at a time, and may also exclude other components of interest. It was therefore the intention of this work to develop a method which would determine a wide range of sulphite binders in a single chromatographic run.

The method chosen for development was the classical reaction between carbonyls and dinitrophenylhydrazine (DNPH) to give stable coloured dinitrophenylhydrazones. These are chromatographically well behaved, have a strong and distinctive chromophore at $365 \mathrm{~nm}$, and have been used to determine aldehydes and ketones by HPLC in a number of systems (Dahlgran \& Jameson, 1988; Edelkraut \& Brockmann, 1990). The DNPH adducts are selectively generated by carbonyls and should reflect those compounds most likely to form sulphite adducts in fermented ciders (Fig. 1).

\section{Reaction conditions and kinetics}

Classically, the DNPH reaction is usually carried out in saturated aqueous solution under acidic conditions, to encourage the formation of an insoluble derivative which can be isolated and characterized (e.g. by melting point). For HPLC, however, it is an advantage for the derivatives to stay in solution. The final conditions chosen therefore employ an excess of dinitrophenylhydrazine in acidic acetonitrile to achieve this.

It was determined that acetaldehyde reacts to completion with the derivatizing reagent at room temperature almost immediately, whereas pyruvate

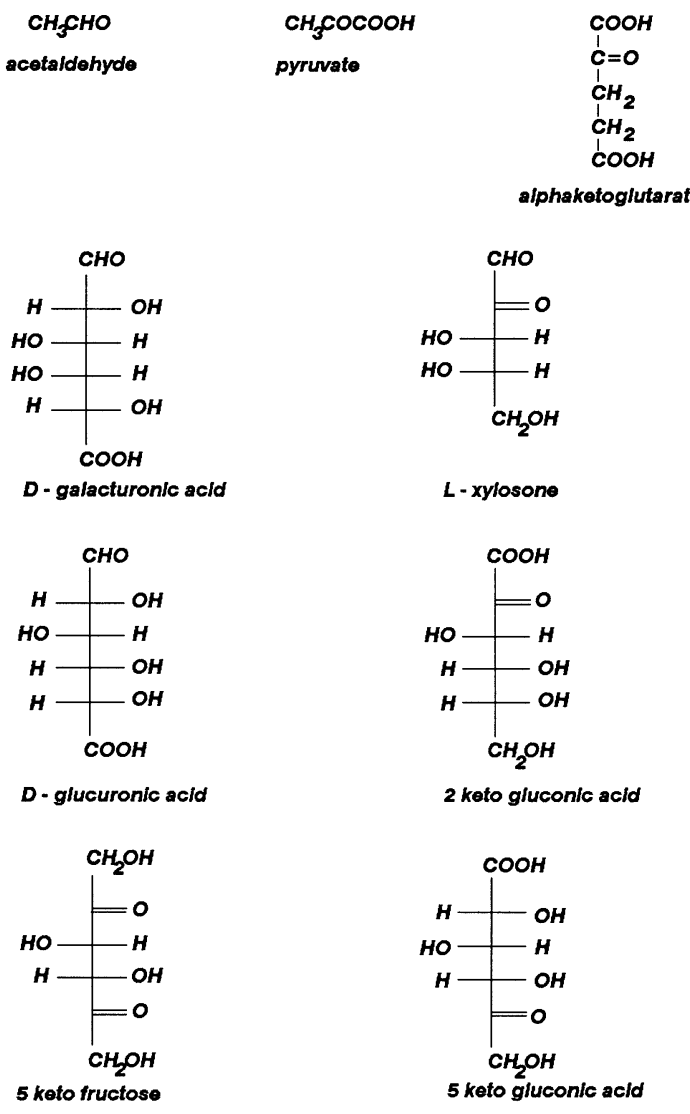

Figure 1 Sulphite binding carbonyl components likely to be present in ciders.

and $\alpha$-ketoglutarate require up to $2 \mathrm{~h}$. Hexose derivatives, such as glucose and galacturonic acid, require to be derivatized overnight for completion of the reaction. Heating of the reaction was investigated as an alternative but abandoned, since it led to the formation of multiple peaks with longer wavelength chromophores, particularly from hexose derivatives. It is probable that these were dinitrophenylosazones, in which two moles of DNPH are bound per mole of sugar. In practice, overnight derivatization at room temperature gave stable and reproducible results when a mixed standard was carried through the procedure at the same time.

\section{Chromatographic conditions}

Initial work was carried out on a Spherisorb ODS2 column (Phase-Sep, Deeside, UK) in an acidified water/acetonitrile gradient. This gave good resolution 
for the simpler derivatives, but poor peak shape for the early eluting hexose derivatives, even when the injection solvent was adjusted appropriately. Better chromatography of these early peaks was eventually obtained on a Spherisorb Hexyl packing (Phase-Sep Ltd). However, if alternative methods for the analysis of glucose and galacturonic acid are available, such as ion chromatography, these may be preferred for the easier determination of these components, and an ODS2 column may then be used for the non hexose carbonyls.

\section{Effect of bound $\mathrm{SO}_{2}$}

In simple model systems the carbonyls reacted smoothly and completely. In sulphited commercial ciders, however, or in model systems with added $\mathrm{SO}_{2}$, the derivatization was dependent upon the extent of existing $\mathrm{SO}_{2}$ binding. That is, the most tightly sulphite bound carbonyls were not free to react with the DNPH reagent, even at $\mathrm{pH} 1$ where some dissociation from sulphite is known to occur (Burroughs \& Sparks, 1973a). This was particularly noticeable for acetaldehyde, where recoveries were as little as $25 \%$ of the theoretical.

To overcome this problem, a regime was developed in which ciders were first treated with strong alkali for $10 \mathrm{~min}$ to dissociate the sulphite complex such a treatment is commonly used to dissociate the acetaldehyde-sulphite complex during the Ripper iodine titration for total $\mathrm{SO}_{2}$ measurement. The samples were then acidified and immediately derivatized with DNPH. Since the kinetics of recombination with sulphite are relatively slow, the DNPH is able to form the required hydrazones before any significant addition of sulphite can occur. This procedure gave full recovery of carbonyls as the DNPH adducts, even from systems containing 250 $\mathrm{mg} \mathrm{L}^{-1}$ total $\mathrm{SO}_{2}$. Unfortunately, the alkaline treatment appeared to destroy L-xylosone. If this component is to be determined, therefore, a second set of untreated samples must be derivatized and assayed, using a detection wavelength of $430 \mathrm{~nm}$ to enhance the sensitivity for this derivative.

\section{HPLC method}

\section{Reagent}

The derivatizing reagent was made up by dissolving
$200 \mathrm{mg}$ of solid dinitrophenylhydrazine in $100 \mathrm{~mL}$ acetonitrile. Perchloric acid $(4 \mathrm{~mL}$ of a $60 \%$ aqueous solution) was then added.

\section{Procedure}

To $1 \mathrm{~mL}$ of cider sample was added $0.4 \mathrm{~mL}$ of $1 \mathrm{M}$ $\mathrm{NaOH}$ solution. The solution was allowed to stand for $10 \mathrm{~min}$, followed by the addition of $0.6 \mathrm{ml}$ of $1 \mathrm{M}$ nitric acid. The reaction flask was shaken briefly and $2 \mathrm{~mL}$ of the derivatizing reagent was then added without delay. The reaction was left overnight for chromatography on the following day. Standard solutions were carried through exactly the same procedures. The use of preprepared DNPH derivatives as solid standards offers no advantage owing to the tedium of their preparation to an acceptable degree of purity and dryness (except for L-xylosone which is unstable in the free state). For L-xylosone determination, the sequential addition of alkali and acid must be avoided and a separate analytical sample must be prepared.

\section{Chromatography}

A Spherisorb Hexyl column (150 x $4.6 \mathrm{~mm}$ ) (PhaseSep Ltd) was operated at $45{ }^{\circ} \mathrm{C}$ at a flow rate of 1 $\mathrm{mL} \min ^{-1}$ using a Spectra-Physics SP8800 pumping unit (Thermo Separations, Stone, Staffs., UK) with the gradient as shown in Table 1 .

Detection was at $365 \mathrm{~nm}$, using a Hewlett-Packard 1040 Diode Array detector (Agilent Technologies, Bracknell, UK). The derivatized samples were diluted $1: 1$ with acidified water immediately before injection of $25 \mu \mathrm{L}$ aliquots without filtration. This gives a final concentration of $25 \%$ acetonitrile, which is appropriate for chromatography. Without such dilution, peak shapes of the early running compounds are badly corrupted. Alternatively, an injection

Table 1 HPLC Gradient Solvent Composition

\begin{tabular}{lll}
\hline $\begin{array}{l}\text { Time } \\
\text { (mins) }\end{array}$ & $\begin{array}{l}\text { Water } \\
\text { (ca pH 1.5)* }\end{array}$ & Acetonitrile \\
\hline 0 & 80 & 20 \\
30 & 20 & 80 \\
35 & 80 & 20 \\
\hline
\end{tabular}

*add $10 \mathrm{~mL}$ of $60 \%$ perchloric acid solution to 1 litre of water 


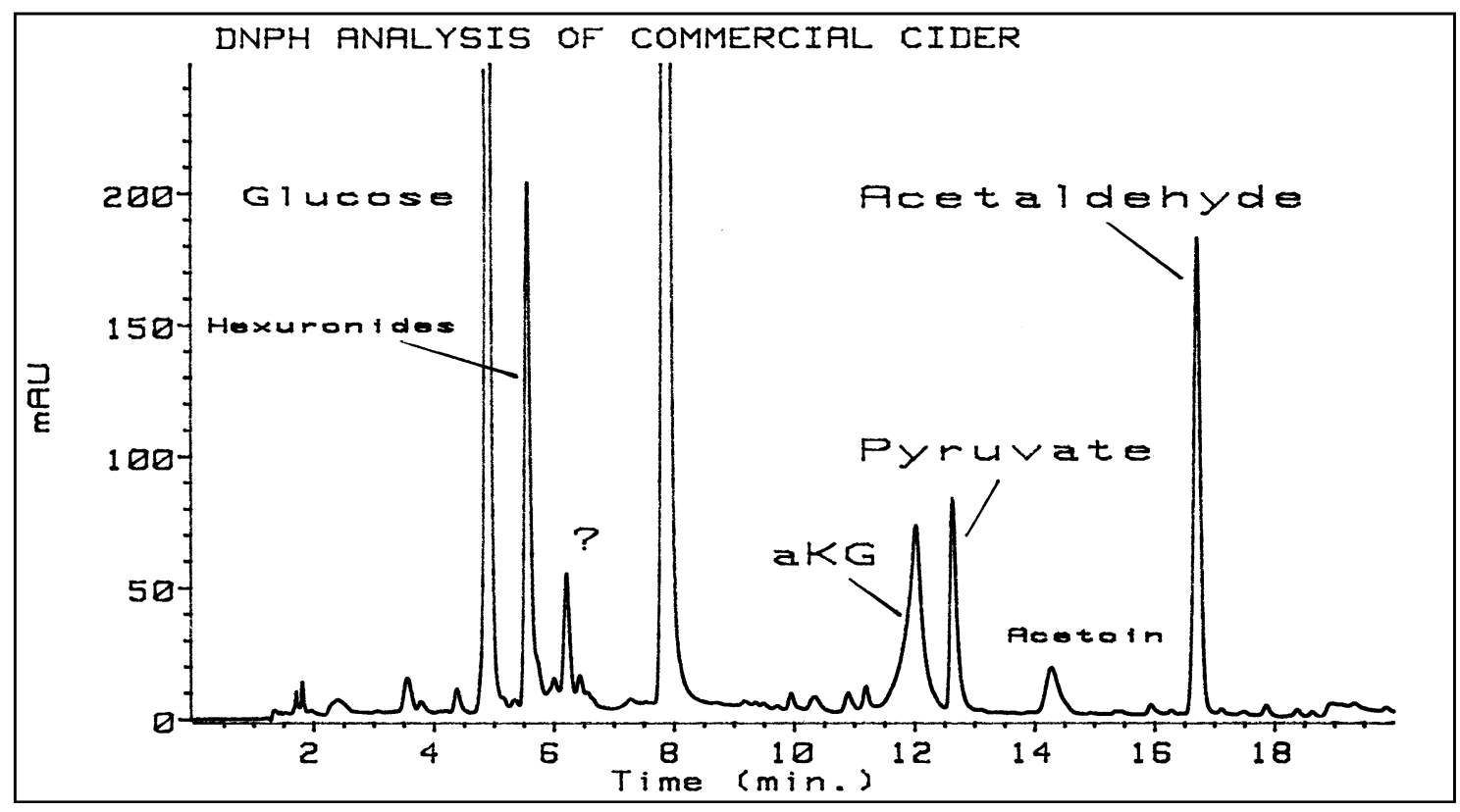

Figure 2 HPLC chromatogram of carbonyls in a commercial cider.

volume $<10 \mu \mathrm{L}$ can be used and the dilution omitted.

Typical retention times obtained on standard solutions are shown in Table 2 , and a typical chromatogram for a commercial cider is shown in Fig. 2.

Standards of 2,5 diketogluconic acid and of 5-keto fructose were not available for study. The chromatography showed that good response and resolution may be obtained for the three major binders, $\alpha$ ketoglutarate, pyruvate and acetaldehyde. The peak

Table 2 Standard retention times and carbonyl concentrations in a canned commercial cider

\begin{tabular}{lll}
\hline Compound & $\begin{array}{l}\text { Retention } \\
\text { time (mins) }\end{array}$ & Concentration $\left(\mathbf{m g ~ L} \mathbf{~}^{-\mathbf{1}}\right.$ ) \\
\hline Glucose (major peak) & 4.9 & 2000 \\
Galacturonic acid & 5.6 & 436 \\
Glucuronic acid & 5.6 & - \\
2-keto gluconic acid & 5.8 & Not observed \\
5-keto gluconic acid & 6.4 & Not observed \\
$\alpha$-keto glutarate & 12.0 & 74 \\
Pyruvate & 12.5 & 33 \\
Acetoin & 14.2 & 5 \\
Acetaldehyde & 16.6 & 15 \\
L-xylosone & 17.0 & Not determined \\
\hline
\end{tabular}

shape for $\alpha$-ketoglutarate was broad, probably owing to isomerization of the DNPH derivative, but this was characteristic both in samples and in standards and it did not interfere with quantification. Galacturonic and glucuronic acids co eluted - these are classed as 'hexuronides' in Figure 2. Acetoin appeared to give a major and some minor peaks, but the standard sample used had deliquesced and was not pure (samples which had undergone malolactic fermentation appeared to have increased values of acetoin). Lxylosone gave a major and a minor peak which could not be purified further (see later).

\section{Method validation}

The HPLC method as presented here was developed some ten years ago as a modern substitute for the Burroughs and Sparks procedure (1964), specifically for use in a comparative series of studies of sulphite binding which are reported separately (Jarvis and Lea, 2000). Formal analytical validation procedures, such as multi level standard additions for determination of recoveries and calibration linearities, were not carried out as part of this work. However, to demonstrate that the method was appropriate for the task in hand, a limited comparison was carried out on three ciders which were analyzed in duplicate 
for the three metabolic carbonyls by the HPLC method as well as by conventional enzymic analysis procedures (enzymes and experimental protocols from Boehringer Mannheim (now Roche Diagnostics), Lewes, UK).

The data obtained is shown in Table 3, from which it may be seen that the results by both procedures are generally well replicated and consistent. The biggest discrepancy between techniques arose in the estimation of $\alpha$-keto glutarate, but these limited data do not give any grounds to favour the enzymic technique over the HPLC or vice versa. Indeed the general agreement between the data sets provided an encouragement to continue with the use of the HPLC technique for its intended purpose. Formal validation of this method to modern analytic quality standards would nonetheless be desirable.

\section{Determination of experimental sulphite binding power}

A standard stock solution of $\mathrm{SO}_{2}$ was made up by dissolving $16.7 \mathrm{~g}$ of sodium metabisulphite in $1 \mathrm{~L}$ of water. Freshly opened packs of cider were bulked and subdivided into 4 × $200 \mathrm{~mL}$ aliquots - a further $100 \mathrm{~mL}$ sample was retained deep frozen for subsequent carbonyl analysis and calculation of the predicted binding curve. The $200 \mathrm{~mL}$ aliquots were spiked in screw capped Duran bottles with nominal quantities of $0,50,100$ and $150 \mathrm{ppm}$ of $\mathrm{SO}_{2}$ by adding $0,1,2,3 \mathrm{~mL}$ of the stock solution. The bottles were then tightly closed and left for $48 \mathrm{~h}$ at room temperature to equilibrate, before analysis for both free and total $\mathrm{SO}_{2}$ as follows.

\section{Analysis of $\mathrm{SO}_{2}$ by a modified Monier- Williams technique}

The following reagents were used: phosphoric acid $88 \%$; hydrogen peroxide $0.2 \%(0.7 \mathrm{~mL}$ of $100 \mathrm{vol}$ solution dissolved in $100 \mathrm{~mL}$ water) prepared fresh daily, and $0.01 \mathrm{M} \mathrm{NaOH}$ prepared fresh daily.

The apparatus was a three headed $250 \mathrm{~mL}$ round bottom flask in an electric heating mantle, fitted with a nitrogen inlet capillary, a dropping funnel for addition of acid and an outlet via a Liebig condenser passing through three sequential traps each formed by a $25 \mathrm{~mL}$ boiling tube and a Dreschel head.

For the determination of total $\mathbf{S O}_{2}$ the following procedure was adopted. Twenty $\mathrm{mL}$ of sample was pipetted into the distillation flask with a few antibumping granules. Indicator (15 drops) was added to $50 \mathrm{~mL}$ of the peroxide solution and neutralized by the dropwise addition of alkali (purple to green). The neutralized solution was then divided equally between each trap. The nitrogen flow through the distillation flask and traps was adjusted to approximately 1 bubble per second and $5 \mathrm{~mL}$ of phosphoric acid was added to the flask from the dropping funnel. The flask was heated quickly to boiling and simmered for $15 \mathrm{~min}$ while continuing to pass nitrogen. The cooling water was then switched off until the top of the condenser became warm. The nitrogen flow was then released and the traps removed. Those traps which had turned purple (generally the first two) were then combined and titrated against $0.01 \mathrm{M}$ alkali. The total $\mathrm{SO}_{2}\left(\mathrm{mgL}^{-1}\right)$ was calculated from the expression $\mathrm{T} \times 16$ (where $\mathrm{T}$ is the titre in $\mathrm{mL}$ ).

For the determination of free $\mathbf{S O}_{2}$ the following modifications were made. A $50 \mathrm{~mL}$ sample was pipetted into the distillation flask. Nitrogen was passed at 2-3 bubbles per second but the flask was not heated, and $15 \mathrm{~mL}$ of phosphoric acid was added from the dropping funnel. After $15 \mathrm{~min}$ the nitrogen was disconnected and the traps removed and titrated against $0.01 \mathrm{M}$ alkali. The free $\mathrm{SO}_{2}\left(\mathrm{mgL}^{-1}\right)$ was calculated from the expression $\mathrm{T} \times 6.4$ (where $\mathrm{T}$ is the titre in $\mathrm{mL}$ ). In all other respects the procedure was the same.

Table 3 Carbonyl assays by both HPLC and enzymic procedures (results in $\mathrm{mgL}^{-1}$ )

\begin{tabular}{|c|c|c|c|c|c|c|c|c|c|c|c|c|}
\hline \multirow[b]{3}{*}{ Acetaldehyde } & \multicolumn{4}{|c|}{ Commercial cider 1} & \multicolumn{4}{|c|}{ Commercial cider 2} & \multicolumn{4}{|c|}{ Experimental cider } \\
\hline & \multicolumn{2}{|c|}{ Enzymic } & \multicolumn{2}{|c|}{ HPLC } & \multicolumn{2}{|c|}{ Enzymic } & \multicolumn{2}{|c|}{ HPLC } & \multicolumn{2}{|c|}{ Enzymic } & \multicolumn{2}{|c|}{ HPLC } \\
\hline & 27 & 28 & 27 & 27 & 13 & 14 & 13 & 14 & 50 & 57 & 61 & 63 \\
\hline$\alpha$-Keto glutarate & 7 & 10 & 8 & 8 & 23 & 25 & 32 & 30 & 36 & 36 & 26 & 26 \\
\hline Pyruvate & 4 & 4 & 3 & 3 & 6 & 7 & 6 & 8 & 37 & 35 & 36 & 35 \\
\hline
\end{tabular}


To plot the experimental binding curve using the eight determined values, the bound $\mathrm{SO}_{2}$ was calculated from the difference between the free and total $\mathrm{SO}_{2}$ for each pair. Values of free $\mathrm{SO}_{2}$ (x-axis) and bound $\mathrm{SO}_{2}$ (y-axis) were then plotted against each other for each pair to give the experimentally observed sulphite binding curves shown in the accompanying publication (Jarvis \& Lea, 2000).

\section{Determination of predicted sulphite- binding power}

The discussion which follows is based on the work of Burroughs \& Sparks (1973a, b, c) whose papers provide a fuller background to this topic.

The major carbonyl sulphite binding components in ciders, together with their molar equilibrium binding constants and molecular weights, are shown in Table 4.

From the Law of Mass Action, the following relationship applies for each carbonyl compound in the cider in the presence of free $\mathrm{SO}_{2}$

$$
K=[\mathrm{S}][\mathrm{X}-\mathrm{x}] /[\mathrm{x}]
$$

where $K=$ the molar equilibrium constant; [S]: the molecular concentration of free $\mathrm{SO}_{2}$ in the whole system; $[\mathrm{X}]$ : the molecular concentration of total carbonyl; and $[\mathrm{x}]$ : the molecular concentration of bisulphite bound carbonyl.

In a mixed system with several carbonyl compounds each in equilibrium with the existing free $\mathrm{SO}_{2}$, the amount of each carbonyl bound by $\mathrm{SO}_{2}[\mathrm{x}]$ can be calculated if the values of $[\mathrm{S}],[\mathrm{X}]$ and $K$ are known. The constant $K$ is determined empirically as an 'apparent equlibrium constant' where $[\mathrm{x}]$ is expressed as the number of moles of sulphite which are bound. The sum of the separate values of $[\mathrm{x}]$ therefore gives the bound $\mathrm{SO}_{2}$ content of the whole system. Hence by analysing the carbonyl content of the cider and calculating the equilibrium as above for each component, the bound $\mathrm{SO}_{2}$ content of the system can be predicted for any chosen value of free $\mathrm{SO}_{2}$. Equally, these values of bound and free $\mathrm{SO}_{2}$ can be experimentally determined and should agree with the prediction (if all the binding carbonyls are known).

The plot of bound $\mathrm{SO}_{2}$ versus free is not necessarily a straight line. This is because, in a multicomponent system containing different concentrations of carbonyls with various equilibrium constants, the $\mathrm{SO}_{2}$ is preferentially bound to those carbonyls with the smallest values of $K$. Thus not until nearly all the acetaldehyde is bound to $\mathrm{SO}_{2}$ will the remaining carbonyls begin to be significantly bound. The shape of the curve therefore depends on the relative concentrations of the different binding compounds and their $K$ values. In practice, free acetaldehyde and free $\mathrm{SO}_{2}$ cannot co-exist in a cider and more than $99 \%$ of the acetaldehyde will be bound before any free $\mathrm{SO}_{2}$ can be determined. Conversely, less than $0.1 \%$ of the total glucose is generally sulphite bound in a cider, despite its relatively high concentration, because its $K$ value is relatively large.

To calculate the predicted binding power, the Mass Action equation is rewritten in the following form:

$$
[\mathrm{X}]=[\mathrm{X}] /\{(K /[\mathrm{S}])+(1)\}
$$

\begin{tabular}{|c|c|c|c|c|c|c|c|}
\hline \multirow[t]{2}{*}{ Compound } & \multirow[t]{2}{*}{$\begin{array}{l}\text { Equilibrium } \\
\text { constant }\end{array}$} & \multirow[t]{2}{*}{$\begin{array}{l}\text { Molecular } \\
\text { weight } \\
\text { (K) }\end{array}$} & \multirow[t]{2}{*}{$\begin{array}{l}\text { Concentration } \\
\left(\mathrm{mg} \mathrm{I}^{-1}\right)\end{array}$} & \multicolumn{4}{|c|}{$\begin{array}{l}\text { Bound } \mathrm{SO}_{2}\left(\mathrm{mg} \mathrm{I}^{-1}\right) \\
\text { at the following levels } \\
\text { of free } \mathrm{SO}_{2}\end{array}$} \\
\hline & & & & 8 & 25 & 45 & 72 \\
\hline Acetaldehyde & $1.5 \times 10^{-6}$ & 44 & 38 & 55 & 56 & 56 & 56 \\
\hline Pyruvate & $1.6 \times 10^{-4}$ & 88 & $15 / 9$ & 5 & 7 & 9 & 9 \\
\hline$\alpha$-Keto glutarate & $5.6 \times 10^{-4}$ & 146 & 22 & 2 & 4 & 5 & 7 \\
\hline Galacturonic acid & $1.8 \times 10^{-2}$ & 212 & 2030 & 4 & 13 & 23 & 36 \\
\hline Glucose & $6.4 \times 10^{-1}$ & 181 & 7250 & 1 & 2 & 3 & 4 \\
\hline TOTAL & & & & 67 & 82 & 96 & 112 \\
\hline EXPERIMENTALLY OBSERVED & & & & 55 & 75 & 85 & 104 \\
\hline
\end{tabular}

Table 4 Bound $\mathrm{SO}_{2}$ attributable to carbonyl compounds at different values of free $\mathrm{SO}_{2}$

Equilibrium constants from Würdig 1989. Data from Product Code 12 (Jarvis \& Lea, 2000) 
This gives the amount of bound carbonyl at the chosen value of free $\mathrm{SO}_{2}$. The calculation is therefore performed for each carbonyl, and the various values of $[\mathrm{x}]$ are added together to give the bound $\mathrm{SO}_{2}$ value at the chosen value of free $\mathrm{SO}_{2}$ (typically, $50 \mathrm{mg} \mathrm{L}^{-1}$ is chosen when spot comparisons between samples are to be made). For a curve to be plotted, all the calculations must be performed for at least four evenly spaced values of free $\mathrm{SO}_{2}$. If predicted and experimental curves are to be compared, then the values of free $\mathrm{SO}_{2}[\mathrm{~S}]$ chosen for this exercise should be those which were determined empirically on the same samples after addition of controlled amounts of $\mathrm{SO}_{2}$. The calculations may be set up on a spreadsheet to give $[\mathrm{x}]$ for any desired value of $[\mathrm{S}]$, since $[\mathrm{X}]$ remains constant for any given sample and $K$ is a fixed constant for each carbonyl. Note that $[\mathrm{X}]$ and [S], although generally determined and reported as $\mathrm{mg} \mathrm{L}^{-1}$, must be converted to molar quantities for the calculation. Similarly, $[\mathrm{x}]$ must be converted back to $\mathrm{mg} \mathrm{L}^{-1}$ for final reporting (the molecular weight of $\mathrm{SO}_{2}$ is 64).

Table 2 shows the predicted values obtained for a commercial cider (product 12 Jarvis \& Lea, 2000) following this calculation routine. The values obtained experimentally are also given for comparison. Curves plotted from this data are shown in the accompanying publication (Jarvis \& Lea, 2000).

\section{Preparation of L-xylosone}

The method originally given by Whiting \& Coggins (1960), using iodine oxidation of ascorbic acid to dehydroascorbate followed by sulphite oxidation and decarboxylation to L-xylosone, did not work satisfactorily in our hands. Following a literature reference by Shin \& Feather (1990), and the gift of a small impure sample of L-xylosone from Dr Feather, we investigated their procedure and found it more satisfactory. This had been originally described by Salomon et al. (1952), and depends on the selective oxidation of L-xylose to L-xylosone by cupric acetate.

Solid L-xylose (1.6 g) was dissolved in water (7 $\mathrm{mL})$. To this was added methanol $(100 \mathrm{~mL})$ and powdered cupric acetate monohydrate $(7 \mathrm{~g})$. The solution was slowly refluxed, for $20 \mathrm{~min}$ with stirring, in a $250 \mathrm{~mL}$ flat bottomed flask fitted with a condenser. The solution was allowed to cool and the red cuprous oxide was removed by centrifugation for $10 \mathrm{~min}$ at 2700 r.p.m. The supernatant was rotary evaporated to reduce the volume by removing most of the methanol.*

Attempts were made to purify the xylosone away from unreacted xylose and cupric acetate by ion exchange chromatography as described by the previous workers. The column fractions were then derivatized to their DNPH forms and monitored by HPLC and TLC, followed by preparative TLC. The fraction corresponding to xylosone DNPH (as determined by its NMR spectrum) was generated only in low yield, and the concentrated xylosone before derivatization did not remain stable.

The purification of pure L-xylosone in the free state was therefore abandoned, and an alternative strategy was developed to generate the L-xylosone DNPH adduct directly as the stable and usable form.

\section{Preparation of L-xylosone DNPH derivative}

Solid 2,4 dinitrophenylhydrazine (4 g) was dissolved by warming in $100 \mathrm{~mL}$ of $85 \%$ phosphoric acid. The solution was cooled, $100 \mathrm{~mL}$ of $95 \%$ ethanol added and the solution cooled again (Fieser \& Fieser, 1967). The reaction solution (from *above) was added to $200 \mathrm{~mL}$ of this DNPH solution and left in the refrigerator to precipitate overnight. This was then centrifuged for $10 \mathrm{~min}$ at 3000 r.p.m, and the precipitate washed three times with cold water before being allowed to air dry. A portion of this solid $(1.6 \mathrm{~g})$ was dissolved in $640 \mathrm{~mL}$ of $50 \%$ aqueous acetonitrile over a boiling water bath, filtered while still hot and allowed to cool in a refrigerator for $70 \mathrm{~h}$. The precipitate was then removed by vacuum filtration through a $0.45 \mu \mathrm{m}$ membrane before final drying.

NMR data obtained on this derivative were consistent with the structure of L-xylosone after condensation of the respective aldehydic and ketonic carbonyls with DNPH. The ${ }^{13} \mathrm{C}$ chemical shifts $(\delta)$ obtained in $\mathrm{d}_{6}$ acetone were as follows for the xylosone carbons (numbering from the aldehyde end): $\mathbf{1}$ - 150.8; 2 - 147.2; 3, 4 - 71.0, 73.4; 5 - 62.9. Corresponding data for the DNPH aromatic carbons were as follows (with two signals from each carbon due to the two DNPH substituents): 1 - 144.1, 144.6; 2 - 130.4, 130.6; 3 - 122.8, 123.0; 4 - 138.4, 138.7; 5 - 129.6, 129.8; 6 - 116.0, 117.3).

When dissolved in $20 \%$ acetonitrile and injected onto the HPLC system using the conditions described 
in this paper, a major and a minor peak at ca 17 and 19 min were observed, with absorbance maxima at $430 \mathrm{~m}$. After drying to constant weight, the solid was stored in a refrigerator and was used to prepare standards for quantification of L-xylosone by the HPLC procedure. The proportions of the two peaks (ca $6: 1$ ) could not be changed by further recrystallization, and it was therefore assumed that they constituted two isomers of the di-DNPH derivative. Xylosone is a dicarbonyl and will therefore give a diDNPH adduct. Conjugation between the adjacent DNPH groups is probably the reason for the bathochromic shift in its visible chromophore from 365 to $430 \mathrm{~nm}$.

\section{Acknowledgement}

This work was funded by and carried out for the National Association of Cidermakers, whom we thank for permission to publish this report. We thank Dr John Sheridan for running and interpreting the NMR spectra, and Karen Masters for carrying out the enzymic assays. The support and advice of Professor Basil Jarvis and (the late) Dr Fred Beech are also gratefully acknowledged.

\section{References}

Burroughs, L.F. \& Sparks, A.H. (1964). The identification of sulphur dioxide binding compounds in apple juices and ciders. Journal of the Science of Food and Agriculture, 15, 176-185.
Burroughs, L.F. \& Sparks, A.H. (1973a). Sulphite binding power of wines and ciders I. Equilibrium constants for the dissociation of carbonyl bisulphite compounds. Journal of the Science of Food and Agriculture, 24, 187-198.

Burroughs, L.F. \& Sparks, A.H. (1973b). Sulphite binding power of wines and ciders II. Theoretical considerations and calculation of sulphite binding equilibria. Journal of the Science of Food and Agriculture, 24, 199-206.

Burroughs, L.F. \& Sparks, A.H. (1973c). Sulphite binding power of wines and ciders III. Determination of carbonyl compounds in a wine and calculation of its sulphite binding power. Journal of the Science of Food and Agriculture, 24, 201-217.

Dahlgran, J.R. \& Jameson, M.N. (1988). Determination of formaldehyde and other aldehydes by liquid chromatography of their 2,4 dinitrophenylhydrazone derivatives. Journal of the Association of Official Analytical Chemists, 71, 560-563.

Edelkraut, F. \& Brockmann, U. (1990). Simultaneous determination of carboxylic acids and carbonyl compounds in estuaries by HPLC. Chromatographia, 30, 432-435.

Fieser, L. \& Fieser, M. (1967). Reagents for Organic Synthesis, Vol 1. P330. New York: J Wiley.

Jarvis, B. \& Lea, A.G.H. (2000). Sulphite binding in ciders. IJFST, 35, 113-127.

Salomon, L.L., Burns, J.J. \& King, C.G. (1952). Synthesis of Lascorbic-1-C ${ }^{14}$ acid from D-sorbitol. Journal of the American Chemical Society, 74, 5161-5162.

Shin, D.B. \& Feather, M.S. (1990). 3-deoxy-L-xylosone and Lxylosone as intermediates in the degradation of L-ascorbic acid. Carbohydrate Research, 208, 246-250.

Whiting, G.C. \& Coggins, R.A. (1960). Formation of Lxylosone from ascorbic acid. Nature, 185, 843-844.

Würdig, G. (1989). Behandlung des weines mit schwefliger säure. Chemie des Weines, Würdig, G. \& Woller, H. 329-370. Stuttgart: Ulmer Verlag. 